\title{
STATUS KESEHATAN DAN KETERATURAN PEMANFAATAN LAYANAN INFERTILITAS
}

HEALTH STATUS AND REGULARITY UTILIZATION OF THE INFERTILITY SERVICE

\author{
Fayakun Nur Rohmah \\ Program Studi D3 Kebidanan, Fakultas Ilmu Kesehatan, Universitas 'Aisyiyah Yogyakarta \\ Email : fayakun.nurrohmah@gmail.com
}

\begin{abstract}
ABSTRAK
Pendahuluan : $45 \%$ perempuan infertil primer datang ke pelayanan infertilitas setelah 12 bulan infertil, pada infertil sekunder $37 \%$ dalam 1 tahun pertama. Penelitian ini bertujuan melihat hubungan antara status kesehatan terhadap keteraturan pemanfaatan layanan. Metode : Jenis penelitian ini adalah survei analitik. Teknik pengambilan sampel menggunakan acidental sampling sebanyak 63 perempuan infertil. Analisis data bivariat menggunakan chi square. Hasil : Hasil analisis menunjukkan ada hubungan antara status kesehatan terhadap keteraturan pemanfaatan layanan infertil $(p=0,035)$. Kesimpulan : Kesadaran terhadap status kesehatan meningkatkan keteraturan dalam pemanfaatan layanan infertil.
\end{abstract}

Kata Kunci : Infertilitas, Status kesehatan, keteraturan pemanfaatan layanan

\begin{abstract}
Introduction: $45 \%$ of primary infertile women come to the infertility care after they are infertile for 12 months with $37 \%$ secondary infertile in the first year. This study examines the relationship between health status to the regularity of the utilization of infertility services. Methods: The research is observational analytic research. The sampling technique is accidental sampling of 63 infertile women. The bivariate data analysis uses chi-square. Results: The results shows that there is statistically positive and significant relationship between health status $(p=0.035)$ to the regularity utilization of infertility services. Conclusion: Awareness of the health status will improve the regularity to utilization.
\end{abstract}

Keywords: Infertility, health status, regularity utilization 


\section{PENDAHULUAN}

Permasalahan infertilitas tidak saja merupakan masalah ginekologi, akan tetapi menjadi masalah kesehatan yang serius karena seringkali permasalahan tersebut berdampak pada kualitas hidup pasangan tidak hanya pada fisik, akan tetapi berdampak terhadap psikologis, sosial maupun ekonomi dari individu dan pasangan (Louis et al, 2013; Gokler et al, 2014).

Budaya patriarkhi yang masih kental di Indonesia khususnya di masyarakat. Jawa mengganggap tabu permasalahan infertilitas, bias gender menjadi salah satu faktor yang menghambat pasangan mendapatkan layanan kesehatan infertilitas. Perempuan menjadi pihak yang banyak dirugikan dalam hal infertilitas, stigma masyarakat memandang jika pasangan belum memiliki keturunan maka perempuanlah yang dianggap bersalah (Dermatoto, 2008).

Tingginya tingkat keberalihan layanan ditunjukkan sekitar $76 \%$ perempuan yang berkonsultasi dengan dokter Obsgyn mengaku telah berpindah 1-3 kali untuk mendapatkan terapi infertilitas. Alasan terbanyak (32\%) adalah karena pengobatan oleh dokter yang pertama dianggap tidak berhasil, sebanyak $18 \%$ pasien mancari second opinion, memperoleh informasi lain tentang dokter yang lebih baik (13\%), merasa tidak cocok dengan dokter pemberi layanan, berpindah tempat tinggal $(6 \%)$, menginginkan dokter yang lebih modern (5\%), merasa dokter yang pertama tidak mendengarkan keluhannya (5\%) dan faktor lain (6\%) (Bennett et al, 2012). Hal tersebut secara langsung akan mempengaruhi keberlanjutan terapi yang sudah diberikan pada kunjungan sebelumnya oleh dokter.

Umumnya perempuan yang telah menikah paling lama 2 tahun lebih dari $90 \%$ akan hamil. Seiring bertambahnya usia tatalaksana secara medis akan lebih kompleks dibandingkan dengan pasangan infertil yang sedini mungkin mendapatkan terapi infertilitas, sehingga biaya terapi cenderung meningkat. Faktor pembiayaan tersebut mempengaruhi keberlanjutan terapi pada pasangan infertil karena tindakan dan terapi infertilitas tidak masuk dalam jaminan kesehatan (Chhabbra et al. 2012).

Status kesehatan menjadi faktor penting dalam peningkatan pemanfaatan pelayanan kesehatan. Bukti menunjukkan bahwa status kesehatan yang lebih rendah dari populasi secara langsung menyebabkan peningkatan pemanfaatan semua jenis layanan kesehatan baik kunjungan ke klinik, dokter, dan rumah sakit (Saragih, 2010).

Kesinambungan pemanfaatan layanan kesehatan merupakan perilaku kesehatan yang diharapkan muncul sebagai bentuk minat individu terhadap kepentingan kesehatannya untuk peningkatan kualitas hidupnya dan didukung adanya dukungan sosial dari masyarakatserta kemudahan akses tentang kesehatan (Maulana, 2014).

Banyaknya fenomena pasangan infertilitas menunda kunjungan ke layanan infertilitas dan tingginya angka keberalihan yang menyebabkan tidak teraturnya kunjungan ke layanan kesehatan menarik peneliti untuk lebih dalam menggali tentang hubungan status kesehatan dengan pemanfaatan layanan infertilitas di klinik Sekar Moewardi sebagai klinik yang 
memberikan layanan masalah infertilitas.

Temuan penelitian ini diharapkan memiliki implikasi teoritis bahwa teori The Anderson Model of Health Care Utilization dapat digunakan untuk menjelaskan faktor yang berhubungan dengan keteratutan pemanfaatan layanan infertilitas.

\section{METODE PENELITIAN}

Penelitian ini merupakan survei analitik, dengan pendekatan waktu crooss sectional. Subjek kasus dalam penelitian adalah perempuan yang melakukan kunjungan ulang terkait masalah infertilitas ke klinik Sekar Moewardi Surakarta. Sampel diambil dengan teknik accidental sampling selama bulan Juni dan Juli 2015 sebanyak 63 responden. Pengambilan data menggunakan kuisioner tertutup.

\section{HASIL DAN PEMBAHASAN}

Karakteristik subjek penelitian yaitu umur, tingkat pendidikan, jenis pekerjaan, jenis infertil dan lama menikah.

Tabel 1. Karakteristik umur dan lama menikah

\begin{tabular}{llllll}
\hline Variabel & $\mathrm{N}$ & Mean & $\begin{array}{l}\text { Std. } \\
\text { Dev }\end{array}$ & Min & Max \\
\hline Usia & 63 & 32,69 & 5,58 & 23,00 & 44,00 \\
$\begin{array}{l}\text { Lama } \\
\text { menikah }\end{array}$ & 63 & 5,50 & 3,57 & 0,5 & 17 \\
\hline
\end{tabular}

Tabel 2. Karakteristik Jenis infertil, umur, tingkat pendidikan, status pekerjaan

\begin{tabular}{lcc}
\hline Variabel & $\mathrm{N}$ & $\%$ \\
\hline Jenis Infertil & & \\
Primer & 54 & 85,70 \\
Sekunder & 9 & 14,30 \\
Umur & & \\
$\quad$ < 35 tahun & 35 & 66,03 \\
$\quad \geq 35$ tahun & 18 & 33,97 \\
Tingkat pendidikan & & \\
SD-SMP & 2 & 3,20 \\
SMA-PT & 61 & 96,80 \\
Status pekerjaan & & \\
\hline
\end{tabular}

\begin{tabular}{lll}
\hline Bekerja & 46 & 73,00 \\
Tidak bekerja & 17 & 27,00 \\
\hline
\end{tabular}

Tabel 3. Tabulasi silang status kesehatan dan keteraturan pemanfaatan layanan

\begin{tabular}{|c|c|c|c|c|c|}
\hline Keteraturan & \multicolumn{2}{|c|}{$\begin{array}{l}\text { Kurang } \\
\text { teratur }\end{array}$} & \multicolumn{2}{|c|}{ Teratur } & \\
\hline $\begin{array}{l}\text { Status } \\
\text { Kesehatan }\end{array}$ & $f$ & $\%$ & $f$ & $\%$ & $p$ \\
\hline Kurang baik & 9 & 24,3 & 28 & 75,7 & 0.035 \\
\hline Baik & 13 & 50,0 & 13 & 50,0 & \\
\hline
\end{tabular}

Terdapat hubungan dan secara statistik signifikan antara status kesehatan dengan keteraturan pemanfaatan layanan infertilitas. Penelitian ini penggalian data lebih pada masalah kesehatan dankeadaan yang dirasakan oleh individu, yang merupakan manifestasidan besarnya rasa takut akan penyakitnya dan hebatnya rasa sakit yang dideritanya terutama karena ganguan haid dan riwayat infeksi serta masalah pada organ reproduksi. Kebutuhan menurut Andersen terkait dengan persepsi seseorang untuk memanfaatkan layanan kesehatan, kesadaran akan kebutuhan layanan terkait dengan keluhan yang dirasakan ataupun berdasarkan diagnosis pemberi layanan Kesehatan.

Riwayat reproduksi masa lalu seorang wanita adalah prediktor kuat pencarian pelayanan infertilitas. Hasil penelitian menunjukkan $85,70 \%$ perempuan yang memanfaatkan layanan infertilitas adalah pasien dengan inferti primer. Penelitian serupa menunjukkan kecenderungan pasien infertil primer memanfaatkan layanan infertil karena kehawatiran dan kecemasan terhadap masalah ginekologi lebih besar dibandingkan dengan perempuan dengan infertil sekunder yang pernah hamil maupun melahirkan (Bourne, 2012).

Perempuan nulipara memiliki kemungkinan dua kali lebih besar 
daripada perempuan yang pernah melahirkan. Perempuan yang mengalami masalah ginekologi kemungkinan memanfaatkan layanan kesehatan empat kali dibandingkan dengan perempuan yang tidak memiliki keluhan ginekologi. Hasil penelitian serupa menyatakan perempuan yang memiliki resiko kesehatan dan riwayat komplikasi lebih rutin datang untuk melakukan pemeriksaan (Chhabbra et al, 2012).

Status kesehatan perempuan infertil dilihat dari riwayat haid dan riwayat penyakit perempuan infertil. Siklus haid merupakan variabel yang sangat penting. Siklus haid normal jika dalam kisaran 21-35 hari. Untuk mendapatkan rata-rata siklus haid seseorang perlu diperoleh informasi silkus haid dalam waktu 3-4 bulan terakhir. Perlu juga diketahui apakah adanya keluhan nyeri haid setiap bulannya dan perlu dikaitkan dengan penurunan aktifitas fisik daat haid akibat nyeri atau penggunaan obat penghilang nyeri saat haid terjadi.

Riwayat infeksi alat reproduksi seperti vaginitis, servisitis juga memiliki kaitan erat dengan infertilitas karena dapat meningkatkan resiko kerusakan tuba. $30-50 \%$ kejadian infertil dipengaruhi oleh mioma uteri karena kemungkinan terkait dengan sumbatan pada tuba, sumbatan pada kanalis servikalis atau mempengaruhi implantasi (Anwar, 2014).

Faktor ovarium yang juga berpengaruh terhadap infertillitas adalah kista coklat karena dikaitkan dengan kegagalan ovulasi, kegagalan maturasi oosit dan kegagalan fungsi tuba karena deformitas tuba. Tindakan operasi yang dilakukan pada masalah tersebut jika tidak dilakukan dengan hati-hati justru dapat menyebabkan kegagalan fungsi endometrium dan memperburuk prognosis (Anwar, 2014). $\begin{array}{ccr}\text { Penelitian lain yang } & \text { mendukung } \\ \text { menunjukkan } & 84,8 \% & \text { responden }\end{array}$ menyatakan mencari pengobatan jika menderita sakit yang berat. Responden yang tidak membutuhkan ke pelayanan kesehatan sebagian besar mencari pengobatan dengan membeli obat ke toko obat $(17,4 \%)$, sebanyak $6,5 \%$ responden yang pergi ke fasilitas pengobatan tradisional dikarenakan kepercayaan yang lebih tinggi dibandingkan fasilitas kesehatan modern. Keyakinan dalam kebudayaan masyarakat mempengaruhi praktik, pilihan, selfcare, penggunaan obat-obat rumah, pengobatan tradisional dan pemanfaatan terhadap layanan kesehatan. Sebagian individu tak terkecuali pasangan infertil akan patuh terhadap budaya yang sudah terbentuk di dalam masyarakat (Bourne, 2012).

Sebagian besar perempuan yang teratur memanfaatkan layanan infertil dalam penelitian ini adalah perempuan yang tidak menggunakan pengobatan selain yang didapatkan di pelayanan kesehatan seperti penggunaan pengobatan tradisional termasuk pengobatan herbal, accupresure, atau pijat ditunjukkan dari data bahwa sebanyak $72 \%$ perempuan yang teratur memanfaatkan layanan infertilitas tidak berinisiatif menggunakan layanan selain yang diberikan dari klinik infertilitas walaupun sudah mengetahui status kesehatannya.

Penelitian yang dilakukan di Turki menyatakan sekitar 32,7\% dari 269 wanita yang dinyatakan infertil menggunakan pengobatantradisional. $87,5 \%$ diantaranya mengkonsumi herbal dengan diminum atau di makan, $8 \%$ menggunakan bahan-bahan herbal bukan untuk konsumsi seperti penguapan dan 4,5\% menggunakan kedua metode. Dari sejumlah pengguna layanan tradisional $79,5 \%$ menggunakan layanan tradisonal setelah mengetahui diagnosis infertil. Mayoritas perempuan infertil (91\%) memutuskan sendiri penggunaan pengobatan 
tradisional. Dari pengobatan tersebut $43,2 \%$ perempuan meyatakan tidak merasakan manfaat dari penggunaan pengobatan tradisional dan $31,8 \%$ mengaku merasakan manfaat dari pengobatan tersebut dan tidak ada satupun yang manyatakan bahwa penggunaan pengobatan tradisional menyebebkan gangguan kesehatan pada dirinya (Tashan, 2012).

Pengobatan alternatif merupakan salah satu usaha pelayanan kesehatan yang masih banyak digunakan oleh masyarakat ketika kedokteran modern tidak lagi bisa menyelesaikan masalah kesehatan mereka. Walaupun kadang tidak logis tetapi banyak fakta yang menunjukkan bahwa pengobatan ini mendatangkan kesembuhan bagi mereka. Fenomena ini terjadi akibat pengaruh yang kuat dari berbagai faktor sosial masyarakat terhadap upaya dalam mencari pengobatan, misalnya mahalnya biaya pengobatan modern, distribusi pelayanan kesehatan yang tidak merata dan tidak berhasil menyembuhkan. Banyaknya gugatan malpraktik yang terjadi belakangan ini diduga juga mengurangi kepercayaan masyarakat terhadap kedokteran modern (Goal, 2013).

Konstruksi budaya yang sudah terbentuk di masyarakat khususnya Jawa yang memegang kuat budaya patriarki tak terkecuali dalam pengambilan keputusan. Perempuan dianggap sebagai pelengkap laki-laki yang harus patuh terhadap keputusan suami termasuk dalam memutuskan penggunaan layanan infertilitas. Keadaan tersebut terkadang juga diterima oleh perempuan karena merasa dirinya lemah dan tergantung pada laki-laki. Didukung dengan kutipan karya sastra jawa yang menyebutkan Kewajiban istri itu antara lain melayani suami dengan baik, mengasuh anak, atau dalam istilah Jawa harus pandai masak, macak, dan manak (masak, berhubungan seks dan melahirkan anak). Ada juga tiga hal yang harus dilakukan para istri gemi (hemat), wedi (takut), dan gumati (perhatian). Walaupun perempuan sudah modern namun budaya yang sangat kuat tersebut masih melekat di masyarakat (Dermatoto, 2008).

Kuatnya tuntutan normatif pada pasangan suami-istri untuk memiliki keturunan memaksa pasangan infertil tidak sabar untuk melakukan pengobatan ataupun memastikan sebab dari kegagalan melahirkan keturunan. Penelitian menunjukkan adanya pasangan yang hanya berumur 10 bulan sampai 3 tahun. Padahal mereka belum mengetahui sebab ketidaksuburan itu. Kebanyakan pasangan kurang melakukan pengobatan karena malu untuk melakukan cek medis, bahkan sudah ada asumsi bahwa pihak perempuan yang mandul (Dermatoto, 2008).

Variabel kesehatan merupakan Komponen kebutuhan (need) dalam teori Andersen (1960) variabel tersebut merupakan komponen yang paling langsung berhubungan dengan pemanfaatan layanan kesehatan. Kategori berdasarkan kesakitan yang terjadi meliputi perceived need dan evaluated need. Perceived need merupakan keadaan kesehatan yang dirasakan oleh individu, yang merupakan manifestasi dan besarnya rasa takut akan penyakitnya dan hebatnya rasa sakit yang dideritanya. Sedangkan evaluated need adalah merupakan penilaian dokter yang merawat tentang beratnya penyakit berupa hasil pemeriksaan medis dokter. Klasifikasi kebutuhan dibagi menjadi dua yaitu kebutuhan yang terdeteksi yang berarti stadium dimana penyakit telah ada tetapi belum terdeteksi oleh teknologi kedokteran dan kebutuhan terdeteksi yaitu stadium dimana penyakit telah dapat dideteksi oleh pemeriksaan klinis dan laboratorium (Anies, 2006). 


\section{SIMPULAN}

Secara statistik status kesehatan memiliki hubungan yang signifikan terhadap keteraturan pemanfaatan layanan infertilitas. Status kesehatan yang baik justru akan menurunkan keteraturan pemanfaatan layanan.

\section{DAFTAR PUSTAKA}

Andersen. RM., 1995. Revisiting the Behaviour Model and Access to Medical Care : Does it Matter?. Journal of Health and Science Behaviour 1995. Vol. 36 (March):1-10

Anies, 2006. Waspada Penyakit Tidak Menular Solusi Pencegahan dari Aspek Perilaku dan Lingkungan. Jakarta : PT Elex Media Komputindo

Anwar, M. 2014. Ilmu Kandungan. Jakarta : PT Bina Pustaka Sarwono Prawirodihardjo

Bennett dkk. 2012. Indonesian infertility patients 'health seeking behaviour and patterns of access to biomedicalinfertility care: an interviewer administered survey conducted in three clinics. Journal Reproductive Health 2012, 9:24 Page 1 of 7. (Online). http://www.reproductive-health-jou r nal.com/content/9/1/24

Bourne. PA., 2012. Chronic diseases, self-rated health status, health care utilization and health insurance status of males in a caribbean nation

Chhabbra et al. 2012. Health Seeking
Practices of Infertile Woman. The open reproductive science journal, 2012, 4, 10-13.

Demartoto, A., 2008, Dampak Infertilitas Terhadap Perkawinan (Suatu Kajian. Perspektif Gender) Surakarta, FISIP UNS

Goal, TL., 2013. Pengaruh Faktor Sosiodemografi, Sosioekonomi dan Kebutuhan Terhadap Perilaku Masyarakat dalam Pencarian Pengobatan di Kecamatan Medan Kota Tahun 2013. Medan : Universitas Sumatra Utara

Gokler, dkk. 2014 The Prevalence of Infertility and Loneliness among Women Aged 18-49 Years Who Are Living in Semi-Rural Areas in Western Turkey. Journal International Journal of Fertility and Sterility. Vol 8 (2): 155-162.

Louis, dkk. 2013. The Prevalence of Couple Infertility In The United States From A Male Perspective: Evidence From A Nationally Representative Sample. Journal Andrology. 2013 Sep;1(5):741-8. doi:

10.1111/j.2047-2927.2013.00110.x. Epub 2013 Jul 10. (Online). http://www.ncbi.nlm.nih.gov/pubme d/23843214

Saragih, R., dkk. 2010. Pengaruh Mutu Pelayanan Kesehatan Terhadap Loyalitas Pasien Rumah Sakit Umum Herna Medan

Tashan, ST., dkk. Traditional practices used by the infertile women to become pregnant and their effects on the 
quality of life. International Journal

of nursing practice. Volume 19,

Issue 5 October 2013

Pages 516-522 